No. 06-7

\title{
The Impact of Group Membership on Cooperation and Norm Enforcement: Evidence using Random Assignment to Real Social Groups
}

\author{
Lorenz Goette, David Huffman, and Stephan Meier
}

\begin{abstract}
:
Due to incomplete contracts, efficiency of an organization depends on willingness of individuals to take non-selfish actions, such as cooperating when there is no incentive to do so or punishing inefficient actions by others. Organizations also constitute a social boundary, or group. We investigate whether this social aspect of organizations has an important benefitfostering unselfish cooperation and norm enforcement within the group-but also whether there is a dark side, in the form of hostility between groups. Our experiment provides the first evidence free from the confounding effect of self-selection into groups. Individuals are randomly assigned to different platoons during a four-week period of officer training in the Swiss Army. We conduct choice experiments-simultaneous prisoner's dilemma games, with and without third-party punishment-in week three. Random assignment significantly increases willingness to cooperate with fellow platoon members. Assignment does not lead to hostility, in the sense of vindictive punishment of outsiders, but does affect norm enforcement, enhancing willingness to enforce a norm of cooperation towards fellow platoon members. This suggests that the social aspect of organizations motivates efficient behavior even when ordinary incentives fail and helps to explain practices designed to foster social ties or group identification within an organization.
\end{abstract}

\section{JEL Classifications: C92, D23, D74, J00}

Lorenz Goette is an Assistant Professor at the Institute for Empirical Research in Economics at the University of Zurich and a research affiliate of CEPR. David Huffman is a Research Associate and Deputy Director, Behavioral and Personnel Economics program area, at the Institute for the Study of Labor (IZA) in Bonn, Germany. Stephan Meier is an Economist at the Federal Reserve Bank of Boston's Research Center for Behavioral Economics and Decision-Making. Their e-mail addresses are lorenz@iew.unizh.ch, huffman@iza.org, and stephan.meier@bos.frb.org, respectively.

This paper, which may be revised, is available on the web site of the Federal Reserve Bank of Boston at http://www.bos.frb.org/economic/wp/index.htm.

We are grateful to George Akerlof, Iris Bohnet, Stefano Della Vigna, Armin Falk, Ernst Fehr, Ulrike Malmendier, and Matthew Rabin for helpful comments. We thank the Swiss Army, and, in particular, Hubert Annen, for making this study possible. This paper is part of the Research Priority Program of the University of Zurich on "The Foundations of Human Social Behavior: Altruism versus Egoism."

The views expressed herein are solely those of the authors and not those of the Federal Reserve System or the Federal Reserve Bank of Boston.

This version: March 2006 
Because it is difficult to control behavior completely with incentives and contracts (Prendergast 1999), the success of organizations depends on members' willingness to take unselfish, efficiency-enhancing actions, or on what has variously been called "team spirit" (Kandel and Lazear 1992), "preferences for cooperation" (Rob and Zemsky 2002), or "motivational capital" (Akerlof and Kranton 2005). For example, if workers put in extra effort even if it is not rewarded and sanction selfish behavior by others even when it is costly to do so, their actions may fill the breach left by regular incentive schemes. ${ }^{1}$ Another important feature of organizations is that they constitute a social boundary, or group, determining with whom an individual interacts on a daily basis.

This paper investigates whether the social aspect of organizations has an important benefit: the fostering of non-selfish cooperation and the punishment of norm violation within the group. Although the traditional unit of analysis for studying organizations in economics has been the individual (Camerer and Malmendier 2004), our hypothesis is in line with an alternative view, which holds that membership in a social group transforms individuals, leading to internalized roles, norms, and values that affect behavior. This view has been advanced in social identity theory (see Haslam 2001, for an overview), in work on the economics of identity (Akerlof and Kranton 2000 and 2005) and in the literature on social capital (Putnam 1993; Knack and Keefer 1997; La Porta et al. 1997). We also test a related, long-standing conjecture in sociology and social psychology that group assignment may have a dark side, leading to hostility towards outsiders in the form of vindictive punishment (see Durlauf 1999; Hewstone, Rubin, and Willis 2002). By using random assignment to real social groups, this paper provides the first evidence on the impact of group membership that is un-confounded by self-selection into groups.

\footnotetext{
${ }^{1}$ Reputation and repeated-game incentives can play an important role in deterring selfish behavior, too (see, for example, Milgrom and Roberts 1992). There are many settings, however, where such motives may prove ineffective. For example, discount rates may simply be too high to implement the efficient solution in repeated games (because of, for example, a high exogenous separation hazard), or there may be instances in which the principal cannot monitor agents effectively, but agents on the same level of the hierarchy could. It is these cases that we are concerned with here.
} 
One type of previous evidence comes from studies using existing social groups. For example, Kollock (1998) finds that members of college fraternities are more willing to cooperate with a member of their own fraternity in hypothetical prisoner's dilemma games. Kollock also finds evidence of hostility towards outsiders; individuals are much more likely to prefer the outcome in which they defect and the other cooperates if the other player is a student from another university or is a member of the campus police. In open-ended responses, subjects explained this behavior as arising from dislike or hatred of the out-group. Another example is Bernhard, Fehr, and Fischbacher (2006). They study tribes in Papua New Guinea, using a dictator game with third-party punishment, and find no evidence of hostility between groups in the form of vindictive punishment. They do find evidence of in-group favoritism, or bias: Dictators transfer more to recipients from their own tribe, and punishers are more willing to undertake costly punishment of low contributions when the recipient of the contribution is from the punisher's own tribe. Because the groups in these studies are not randomly assigned, however, and differ strongly in terms of demographics and culture, it is difficult to attribute any of these findings to membership in a social group per se. ${ }^{2}$

A second type of previous evidence comes from laboratory experiments in which subjects are assigned to "minimal" groups. The group is a label, assigned based on some seemingly irrelevant characteristics, such as a preference for paintings by different artists. These studies find that subjects favor their own group, but find inconclusive evidence on the presence of hostility (Tajfel and Turner 1979; Tajfel, Billig, Bundy, and Flament 1971; Rabbie, Schot, and Visser 1989; Mummendey et al. 1992; Yamagishi, Jin, and Kiyonary 1999). While assignment may be random, groups in these studies are artificially imposed by the experimenter and lack

\footnotetext{
${ }^{2}$ Other group studies look at cooperation or trust within and between different religious sects (Fershtman and Gneezy 2001), and between residents of Southern and Northern Europe (Bornhorst, Ichino, Schlag, and Winter 2004). These studies do not find evidence of group bias (each group favoring its own), but rather group discrimination; for example, members of one group (Eastern Jews) are viewed as less trustworthy by members of both groups (Ashkenazic and Eastern Jews). As argued by the authors, this discrimination is likely driven by stereotypes regarding the culture and characteristics of the less favored group. These findings highlight the need to use random group assignment and to eliminate the confounding effects of perceived differences in group characteristics, if the goal is to identify the effect of group membership.
} 
any social content, that is, history of within-group social interaction. This social interaction may be crucial for the nature and strength of group effects that are observed.

We exploit the fact that individuals are randomly assigned to platoons during a fourweek phase of officer training in the Swiss Army. During this training, officers interact almost exclusively with members of their own platoon. This aspect of our design is similar to the classic Robber's Cave Experiment (Sherif et al. 1961), in which 11-year-old boys were randomly assigned to one of two groups in a summer camp and initially kept apart. Their study focused on how the groups treated each other once they were brought together to compete or cooperate in various games. By contrast, there is no institutionalized competition or cooperation between platoons in our study, and we conduct choice experiments that allow us to measure cooperation and punishment within and between groups.

In a simultaneous prisoner's dilemma game, we find significantly more cooperation when subjects interact with a member from their own platoon. This finding is striking, given that the groups are randomly assigned, have existed for only three weeks, and will be dissolved one week later. Importantly, the finding is consistent with in-group favoritism but also with out-group hostility. Subjects may defect more against the out-group simply because they are selfish in this case, or because they actively dislike the out-group. We also find an effect on beliefs: Subjects believe that their own platoon members are more likely to cooperate than outsiders. This could reflect subjects' awareness of how group membership changes peoples' preferences. It could also reflect a direct impact of group membership on beliefs, causing people to believe that own-group members are more cooperative.

We conduct a second experiment in which a third party can punish one of the players in a prisoner's dilemma game. We find that group assignment has an impact on preferences for punishment, heightening willingness to enforce a norm of cooperative behavior toward fellow group members; punishment is especially high when the victim of defection is from the third party's group. We do not find evidence of hostility in the form of vindictive punishment, that is, third parties punishing outsiders more across the board, regardless of their actions. We do find some indication that out-group members are punished more harshly than in-group members in 
one specific case, namely, when they defect and when the victim of defection is from the punisher's own group. However, this interaction effect is not statistically significant.

We conclude that there is little evidence that group membership creates hostility. On the other hand, there is a strong effect of group membership on willingness to act unselfishly in service of the in-group, both in terms of greater cooperation with fellow group members and in terms of enhanced willingness to engage in altruistic punishment (Fehr and Gaechter 2002) when fellow group members are the victim of defection.

\section{Random Group Assignment}

Institutional Background: All Swiss males are required to perform at least 300 days of military service, beginning with 21 weeks of basic training. In week seven, about one-fourth are selected to go through 10 weeks of officer-candidate training. Of these, one-fourth are promoted to officers and continue on to the Joint Officer Training Program (JOTP). Whereas officercandidate training is specific for each branch of service and occurs in separate locations, JOTP brings new officers from all branches of service together, to the same location, for four weeks. Officers are randomly assigned to a platoon at the beginning of JOTP and spend virtually all their time during the day with their platoon. Training involves mainly coursework on principles of security, combat in large military units, logistics, and leadership. At the end of JOTP, the platoons are dissolved and officers are once again sent to separate locations for further, advanced training specific to each branch of service.

We use this assignment as our manipulation of social groups. Assignment to platoons is random and stratified according to the different branches of service. The army intentionally does this to promote exchanges of perspectives among different branches of service.

The assignment mechanism is ideal, in several ways, for investigating the impact of group membership on behavior. First, trainees know that platoon composition is identical and that nobody can choose which platoon to join. Table 1 presents corresponding statistical tests that confirm there are no significant differences in platoon composition by branch of service, education, or age. Second, there is no competition between the groups (or trainees) for evaluations or other resources. Relative performance evaluations were completed previously, in 
candidate training. Third, despite random assignment to platoons, social ties form very quickly. As we show in Table 2, officers report in the questionnaire that they spend significantly more time off-duty with members of their own platoon than with others. This is remarkable in itself, given that 79.8 percent of the trainees know people in other platoons, mostly from earlier stages of their training. Yet, they choose to spend most of what little off-duty time they have with members of their newly assigned group.

\section{The Experimental Design}

We conducted two experiments to examine the impact of random assignment to real social groups on cooperation and norm enforcement.

Experiment 1: Cooperation. The game is a simultaneous prisoner's dilemma. The players, labeled A1 and A2, are each endowed with 20 points. They simultaneously decide whether to keep the points or pass all of them to the other player. Passed points are doubled. Thus, keeping the points equals defection and passing the points equals cooperation.

Experiment 1 involved two treatments. In the in-group treatment, subjects interacted anonymously, except for being informed that the other player was a member of their platoon. The out-group treatment was the same, except subjects were informed that the other player was a member of another (specified) platoon. Group affiliation was clearly marked on the decision sheets. These treatments allow us to examine how group affiliation of the second player affects cooperation. In-group favoritism and inter-group hostility both predict less cooperation in the out-group treatment than in the in-group treatment.

Experiment 2: Norm Enforcement. In Experiment 2, we add players B1 and B2, each endowed with 70 points. B1 can assign up to 10 deduction points to A1, and B2, likewise, to A2. Each deduction point subtracts three points from the A-player. The B-players can condition their choices on the actions of A1 and A2. Thus, Experiment 2 incorporates the possibility of thirdparty punishment (Fehr and Fischbacher 2004), and is suited for examining how norm violations (that is, defections) are punished and what the determinants of punishment are. 
To examine the impact of group membership on norm enforcement, we vary the composition of players in each game. For the remainder of the paper, we refer to the group composition in Experiment 2 from B1's perspective. Thus, A1 always refers to the player that the B-player can punish, while we refer to the other A-player as A2.

Varying the group membership of A1 allows us to look for evidence of inter-group hostility. In the case of hostility, we should see more punishment when B1 is punishing an A1player from a different platoon than when he is punishing a member of his own platoon. We also study how punishment varies with the group affiliation of A2, the person affected by A1's actions. If B1 and A2 are from the same platoon, then B1 might punish A1 more harshly for defection against A2.

Procedures: The experiment was conducted with paper and pencil in a large auditorium, three platoons at a time. Subjects were ordered into the auditorium and did not know of the experiment in advance. Different platoons were seated in separate areas. In each session, if a subject was in an out-group treatment, the other player was from a platoon not present in the room. The experiment lasted 45 minutes, and the subjects earned on average CHF 17.10 (approximately \$13.00). There was no show-up fee.

Overall, 228 subjects participated in the experiments. 116 were assigned the role of Aplayers and participated in Experiment 1. Half were assigned to the in-group treatment, and half to the out-group treatment. After participating in Experiment 1, these same subjects participated as A-players in Experiment 2. This procedure introduces a possible order effect for the A-players, but choices of the A-players in Experiment 2 are not of interest for our purposes. 112 subjects were assigned the role of Bs. They participated only in Experiment 2 and were assigned to one of four treatments. We elicited B-players' deduction points using the strategy method; that is, they specified how many points to deduct from their associated A-player for each possible combination of actions by A1 and A2. After Experiment 2, we elicited beliefs about other players' behaviors in the treatments in which the subjects had participated. Finally, the subjects filled in a short questionnaire. 
Special care was taken to ensure anonymity. Payoffs were mailed to home addresses ten days after the experiment, so subjects learned the outcome of the experiment only after JOTP was over and they were no longer with their platoons.

\section{Results}

We first present results from Experiment 1, showing the impact of randomly assigned groups on cooperation, and then present results of Experiment 2, showing the effect of group membership on punishment.

RESULT 1: Cooperation and expected cooperation of others is significantly higher in the in-group treatment than in the out-group treatment.

As shown in Table 3, 69 percent cooperate if they are paired with an in-group member, whereas only 50 percent do so when playing with an out-group member. The difference is statistically significant (Fisher's exact test, $p<0.05$ ). Thus, in otherwise anonymous interactions, random assignment to real social groups leads to higher cooperation between members of the same group compared with interaction between members of different groups.

This treatment difference is also reflected in subjects' beliefs. As shown in the second data column of Table 3, subjects in the in-group treatment expect 57 percent of their own platoon members to cooperate, whereas subjects in the out-group treatment expect only a 41 percent cooperation rate from members of another platoon (t-test, $p<0.001$ ). In fact, the differential in cooperation is fully reflected in subjects' beliefs. Regressing the decision to cooperate on a dummy variable for the in-group treatment and also the expected cooperation rate, the in-group dummy becomes small and insignificant, whereas beliefs are strongly associated with the decision to cooperate.

The evidence from Experiment 1 shows that group membership has a strong impact on willingness to cooperate. This is consistent with group membership's having an impact on underlying preferences for cooperation, so that people prefer to cooperate with their own group as opposed to cooperating with the out-group, or even actively dislike the out-group and prefer 
to defect as a strategy for harming them. Different beliefs about the likelihood of cooperation by out-group versus in-group members may reflect individuals' awareness of how group membership affects preferences for cooperation. On the other hand, it is possible that group membership has a direct impact on beliefs, which then shape behavior. Previous evidence shows that willingness to cooperate in simultaneous prisoner's dilemma type games is conditional, increasing in the belief that others will also cooperate (for example, see Croson 1998). If group membership changes beliefs, causing individuals to believe that members of their own group are more likely to be cooperative, this could be self-fulfilling, leading to greater rates of cooperation within the group.

Experiment 2 helps somewhat in disentangling preferences and beliefs. Third-party punishers are allowed to condition their punishment on the actions of the A-players, which removes the need to base actions on expectations about the behavior of these individuals. For this reason, Experiment 2 is also better suited for testing for the presence of a taste for harming the out-group (hostility), expressed through vindictive punishment.

RESULT 2: There is no difference in punishment of in- and out-group members.

Panel A of Figure 1 shows punishment behavior of Bs in Experiment 2 as a function of A1's identity. The point estimates show that B1s assign the same deduction points, independent of A1's group affiliation. This holds whether A1 defects or cooperates. ${ }^{3}$ Thus, we find no support for the conjecture that strong group ties, resulting from random assignment to groups, lead to hostility towards outsiders. However, our results show that group membership does have a strong impact on preferences for punishment.

RESULT 3: Punishment is stronger when defection affects an in-group member as opposed to an outgroup member.

${ }^{3}$ As is typical, defection is punished more strongly than cooperation $(p<0.001$, standard errors adjusted for clustering of individuals). There is also some punishment of cooperation, possibly reflecting a desire to equalize the payoffs between A- and B-players. 
Panel B of Figure 1 shows punishment behavior of B1s as a function of A2's identity. B1 assigns significantly more punishment points to A1 for defection if A2 is from B1's platoon. This difference is statistically significant $(p<0.05$, standard errors adjusted for clustering on individuals). Thus, group assignment changes preferences regarding punishment, leading to an increased willingness to enforce a norm of cooperative behavior towards fellow group members. This is consistent with Bernhard, Fehr, and Fischbacher (2006), who observe that third-party punishers impose more deduction points on dictators who give low transfers if the potential recipient of the transfer is from the punisher's own tribe.

We do not observe unconditional hostility towards outsiders, that is, higher punishment regardless of their actions, but it is interesting to investigate whether the out-group is punished more severely than the in-group in one specific case. Bernhard, Fehr, and Fischbacher (2006) find that the most severe punishment of dictators occurs when a dictator gives a low transfer to the punisher's own tribe and the dictator is from a different tribe. Figure 2 compares treatments where $\mathrm{B} 1$ and $\mathrm{A} 2$ are from the same platoon, but where the platoon affiliation of A1 varies. The results are suggestive of an interaction effect, similar to the one observed between the tribes in Papua New Guinea. If B1 and A2 are from the same platoon, A1's defection is punished particularly harshly if he is an out-group member. However, while the point estimates are suggestive of this effect, each comes with a wide margin of error. We are therefore unable to detect a significant impact of varying the group identity of A1 on the motive to enforce cooperation towards the in-group identified in Panel B of Figure 1.

Table 4 summarizes our results regarding norm enforcement in a regression format. It reports regressions of the number of deduction points assigned to A1 on two dummy variables: the first variable equals 1 if A1 belongs to B1's platoon and 0 otherwise; the second equals 1 if A2 belongs to B1's platoon and 0 otherwise. The regressions address a potential shortcoming of the results discussed in Figures 1 and 2, for which standard errors were calculated assuming independent observations. This assumption could be problematic given that two observations in each cell come from the same individual. We address this issue in Table 4 by clustering on individual; that is, we correct the standard errors to allow for arbitrary correlation of the error term across observations for the same individual. 
Column 1 of Table 4 reports the results for the case where A1 defects. As can be seen, the identity of A1 has no impact on punishing behavior. However, A2's identity has a significant impact on deduction points, even with the conservative method used to correct the standard errors. Punishers are more willing to enforce a norm of cooperation towards their own group. Column 2 displays the results for the case where A1 cooperates. The estimates confirm the impression from Figures 1 and 2, that in this case, neither A1's identity nor A2's identity significantly affects B1's deduction points.

In Columns 3 and 4 we report results for the cases where we allow punishment to depend on the interaction between A1 and A2's identity. As before, we are unable to detect the exact origin of the impact of A2's identity on norm enforcement. The coefficient on A2's identity now reflects the case where A1 is from another platoon. Punishment is significantly higher in this case. However, the point estimate for the interaction effect between A1's and A2's identity is negative, indicating that when B1 assigns deduction points to somebody from his own platoon, A2's identity matters less. However, the latter is statistically insignificant in our sample.

\section{Discussion and Conclusions}

This paper tests whether mere membership in a group affects individuals' willingness to cooperate unselfishly, enforce norms, and punish outsiders vindictively. Our experimental design uses random assignment of individuals to real social groups, providing some of the first evidence free from the confounding effects of selection into groups based on individual characteristics. It also provides a stronger group manipulation than is feasible in laboratory experiments that use artificial groups without social content.

After only three weeks, random assignment to a group leads to the formation of social ties and significantly higher cooperation rates within groups than between groups. In an experiment with third-party punishment, we find no evidence that group membership leads to vindictive punishment of outsiders, in contrast to a long-standing conjecture in sociology and social psychology (Durlauf 1999) that mere membership in a group leads to between-group hostility. We do find that group membership increases willingness to enforce a norm of 
cooperative behavior towards fellow group members, similar to what Bernhard, Fehr, and Fischbacher (2006) observe using tribes in Papua New Guinea. This similarity is striking, given the very different cultural settings involved, and suggests that these patterns of behavior are very general.

Our results imply that the social aspect of organizations has an important, additional benefit: the fostering of efficient behavior in the absence of, or in spite of, purely selfish incentives. One interesting question for further research is how the size of a social group affects willingness to cooperate or punish norms, and what the resulting implications are for the optimal size of an organization, or sub-groups within an organization. Another important question is whether demographic differences alone can explain the hostility observed in previous studies or whether it takes the presence of demographic differences and intense social interaction between group members to generate hostility between groups. 


\section{References}

Akerlof, G., and R. Kranton. 2000. “Economics and Identity." Quarterly Journal of Economics 115(3): 715-753.

Akerlof, G., and R. Kranton. 2005. "Identity and the Economics of Organizations." Journal of Economic Perspectives 19(1): 9-32.

Bernhard, H., E. Fehr, and U. Fischbacher. 2006. "Third-Party Punishment Within and Across Groups: An Experimental Study in Papua New Guinea." American Economic Review Papers and Proceedings 95(2), forthcoming.

Bornhorst, F., A. Ichino, K. Schlag, and E. Winter. 2004. “Trust and Trustworthiness Among Europeans: South-North Comparison." Mimeo, European University Institute.

Camerer, C., and U. Malmendier. 2004. "Behavioral Economics of Organizations." Economic Institutions and Behavioral Economics. Yrjö Jahnsson Foundation, forthcoming.

Croson, R. 1998. "Theories of Altruism and Reciprocity: Evidence from Linear Public Goods Games." Wharton School Working Paper.

Durlauf, S. 1999. “The Case 'Against' Social Capital.” Focus 20(3): 1-4.

Fehr, E., and U. Fischbacher. 2004. "Third-Party Punishment and Social Norms." Evolution and Human Behavior 25:63-87.

Fehr, E., and S. Gaechter. 2002. “Altruistic Punishment in Humans.” Nature 415:137-140.

Fershtman, C., and U. Gneezy. 2001. “Discrimination in a Segmented Society: An Experimental Approach." Quarterly Journal of Economics 116(1): 351-377.

Fischbacher, U., S. Gaechter, and E. Fehr. 2001. “Are People Conditionally Cooperative? Evidence from a Public Goods Experiment." Economics Letters 71(3): 397-404.

Haslam, S. A. 2001. Psychology in Organizations: The Social Identity Approach. Thousand Oaks: Sage Publications.

Hewstone, M., M. Rubin, and H. Willis. 2002. "Intergroup Bias." Annual Review of Psychology 53:575-604.

Kandel, E., and E. Lazear. 1992. "Peer Pressure and Partnerships." Journal of Political Economy 100(4): 801-817. 
Knack, S., and P. Keefer. 1997. "Does Social Capital Have an Economy Payoff? A CrossCountry Investigation." Quarterly Journal of Economics 112(4): 1251-1288.

Kollock, P. 1998. “Transforming Social Dilemmas: Group Identity and Co-operation." In Modeling Rationality, Morality, and Evolution, P.A. Danielson, ed., 186-210. Oxford: Oxford University Press.

La Porta, R., F. Lopez-de-Silanes, A. Shleifer, and R. Vishny. 1997. "Trust in Large Organizations." American Economic Review Papers and Proceedings 87(2): 333-338.

Milgrom, P., and J. Roberts. 1992. Economics, Organization and Management. Englewood Cliffs: Prentice Hall.

Mummendey, A., B. Simon, C. Dietze, M. Gruenert, G. Haeger, S. Kessler, S. Lettgen, and S. Schaeferhoff. 1992. "Categorization is Not Enough: Intergroup Discrimination in Negative Outcome Allocation." Journal of Experimental Social Psychology 28:125-144.

Prendergast, C. 1999. "The Provision of Incentives in Firms." Journal of Economic Literature 37(1): 7-63.

Putnam, R. 1993. Making Democracy Work: Civic Traditions in Modern Italy. Princeton: Princeton University Press.

Rabbie, J. M., J.C. Schot, and L. Visser. 1989. "Social Identity Theory: A Conceptual and Empirical Critique from the Perspective of the Behavioral Interaction Model." European Journal of Social Psychology 19:171-202.

Rob, R., and P. Zemsky. 2002. "Social Capital, Corporate Culture, and Incentive Intensity." RAND Journal of Economics 33(2): 243-257.

Sherif, M., O. Harvey, B. Jack White, W.R. Hood, and C. Sherif. 1961. Intergroup Conflict and Co-operation: The Robber's Cave Experiment. Norman: University of Oklahoma.

Tajfel, H., M. Billig, R. Bundy, and C. Flament. 1971. "Social Categorization in Intergroup Behavior." European Journal of Social Psychology 1:149-178.

Tajfel, H., and J. Turner. 1979. "An Integrative Theory of Intergroup Conflict." In The Psychology of Intergroup Relations, W. G. Austin and S. Worchel, eds. Monterey: Nelson-Hall.

Yamagishi, T., N. Jin, and T. Kiyonari. “Bounded Generalized Reciprocity: Ingroup Favoritism and Ingroup Boasting." Advances in Group Processes 16:161-197. 
Table 1 - Test of Randomization

\begin{tabular}{|c|c|c|c|c|c|c|c|c|}
\hline & \multicolumn{4}{|c|}{ Branches of Service } & \multicolumn{3}{|c|}{ Education } & \multirow[t]{2}{*}{ Age } \\
\hline & Infantry & $\begin{array}{l}\text { Mechanized } \\
\text { Infantry }\end{array}$ & $\begin{array}{l}\text { Rescue } \\
\text { Units }\end{array}$ & Other & $\begin{array}{l}\text { Appren- } \\
\text { ticeship }\end{array}$ & $\begin{array}{l}\text { High } \\
\text { School }\end{array}$ & Other & \\
\hline Mean & $23.3 \%$ & $12.8 \%$ & $18.0 \%$ & $45.8 \%$ & $31.4 \%$ & $55.6 \%$ & $12.8 \%$ & 21.58 \\
\hline $\begin{array}{l}\text { s.d. of means } \\
\text { across platoons }\end{array}$ & $5.5 \%$ & $6.2 \%$ & $7.6 \%$ & $10.6 \%$ & $11.8 \%$ & $9.7 \%$ & $11.1 \%$ & 0.53 \\
\hline $\begin{array}{l}\text { Difference } \\
\text { between } \\
\text { platoons ( } p \text { - } \\
\text { value) }\end{array}$ & 0.93 & 0.6 & 0.52 & 0.41 & 0.36 & 0.41 & 0.073 & 0.41 \\
\hline
\end{tabular}

Table 2 - Off-Duty Time Spent with Members of Different Platoons (\# of Times per Week)

\begin{tabular}{lcc}
\hline & $\begin{array}{l}\text { Own } \\
\text { platoon }\end{array}$ & Other platoon \\
\hline Mean & 2.24 & 0.6 \\
$\begin{array}{l}\text { Fraction with zero times per } \\
\text { week }\end{array}$ & $7 \%$ & $53 \%$ \\
$\begin{array}{l}\text { Fraction with more than one } \\
\text { time per week }\end{array}$ & $47 \%$ & $7 \%$ \\
\hline
\end{tabular}

Notes: Number of observations $=216$. The two distributions are significantly different according to a Wilcoxon Signed-Rank test $(p<0.001)$. 
Table 3 - Cooperation and Beliefs in In-Group and OutGroup Treatment

\begin{tabular}{lcc}
\hline \hline & $\begin{array}{c}\text { Fraction deciding } \\
\text { to cooperate }\end{array}$ & $\begin{array}{c}\text { Average } \\
\text { Expected } \\
\text { cooperation rate }\end{array}$ \\
\hline $\begin{array}{l}\text { In-group } \\
\text { treatment }\end{array}$ & $69.4 \%$ & $56.8 \%$ \\
$\begin{array}{l}\text { Out-group } \\
\text { treatment }\end{array}$ & $50.0 \%$ & $40.5 \%$ \\
Test of difference & $\begin{array}{c}\text { Fisher's exact } \\
\text { test: } \\
p<0.05\end{array}$ & $\begin{array}{c}t-\text { test: } \\
\end{array}$ \\
\hline
\end{tabular}

Table 4 - Deduction Points Varying the Identity of A1 and A2

\begin{tabular}{lcccc}
\hline \hline Variable & Column 1 & Column 2 & Column 3 & Column 4 \\
\hline A1 from platoon of B1 $(=1)$ & 0.077 & 0.055 & 0.622 & 0.113 \\
& $(0.624)$ & $(0.487)$ & $(0.830)$ & $(0.604)$ \\
A2 from platoon of B1 $(=1)$ & $1.44^{* *}$ & 0.372 & $1.97^{* *}$ & 0.427 \\
& $(0.610)$ & $(0.505)$ & $(0.782)$ & $(0.678)$ \\
A1 and A2 from platoon of B1 (=1) & & & -1.33 & -0.14 \\
& & & $(1.440)$ & $(1.050)$ \\
Constant & $3.28^{* * * *}$ & $1.77^{* * *}$ & $3.56^{* * *}$ & $1.8^{* * *}$ \\
& $(0.566)$ & $(0.371)$ & $(0.626)$ & $(0.394)$ \\
\hline R squared & 0.136 & 0.0261 & 0.142 & 0.0262 \\
$\mathrm{~N}$ & 221 & 222 & 221 & 222 \\
\hline
\end{tabular}

Notes: Dependent variable: deduction points. Coefficients of OLS regression. Robust standard errors adjusted for clustering on individuals in parentheses. Treatment effects are absorbed. Columns 1 and 3 show the cases where A1 defects, and columns 2 and 4 show the cases where A1 cooperates.

Level of significance: " $0.01<\mathrm{p}<0.05,{ }^{* * * *} \mathrm{p}<0.01$ 


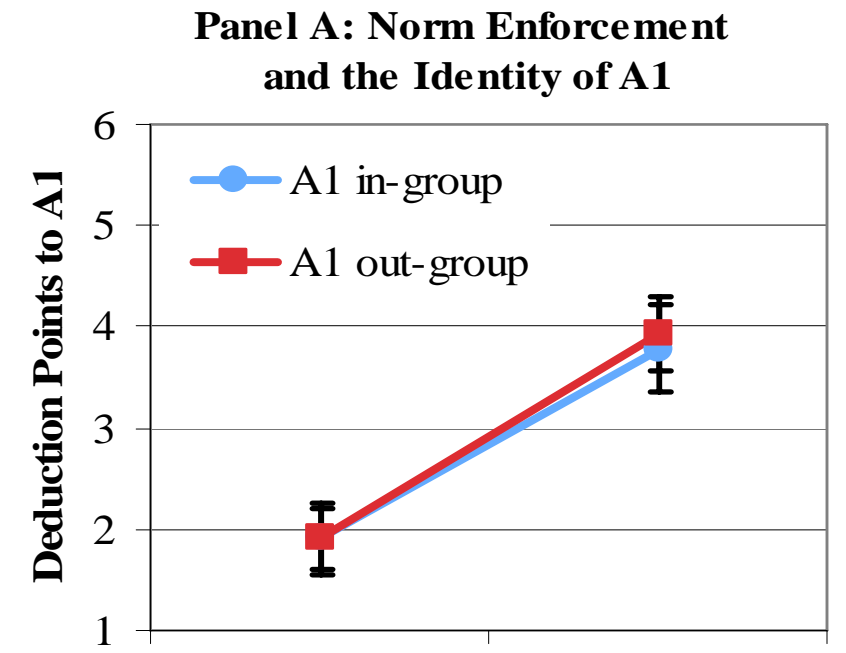

A1 cooperates

Behavior of A1
Panel B: Norm Enforcement and the Identity of A2

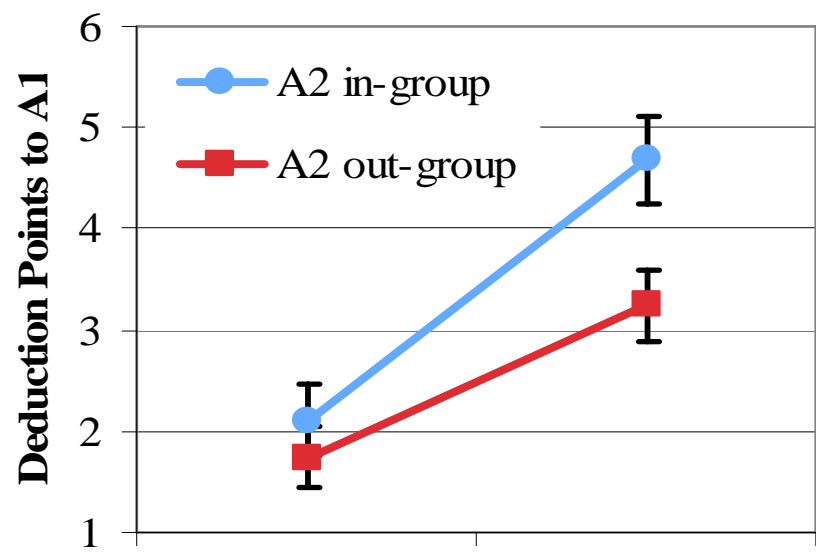

A1 cooperates A1 defects

Behavior of A1

Figure 1: The Impact of Group Membership on Third-Party Punishment. 


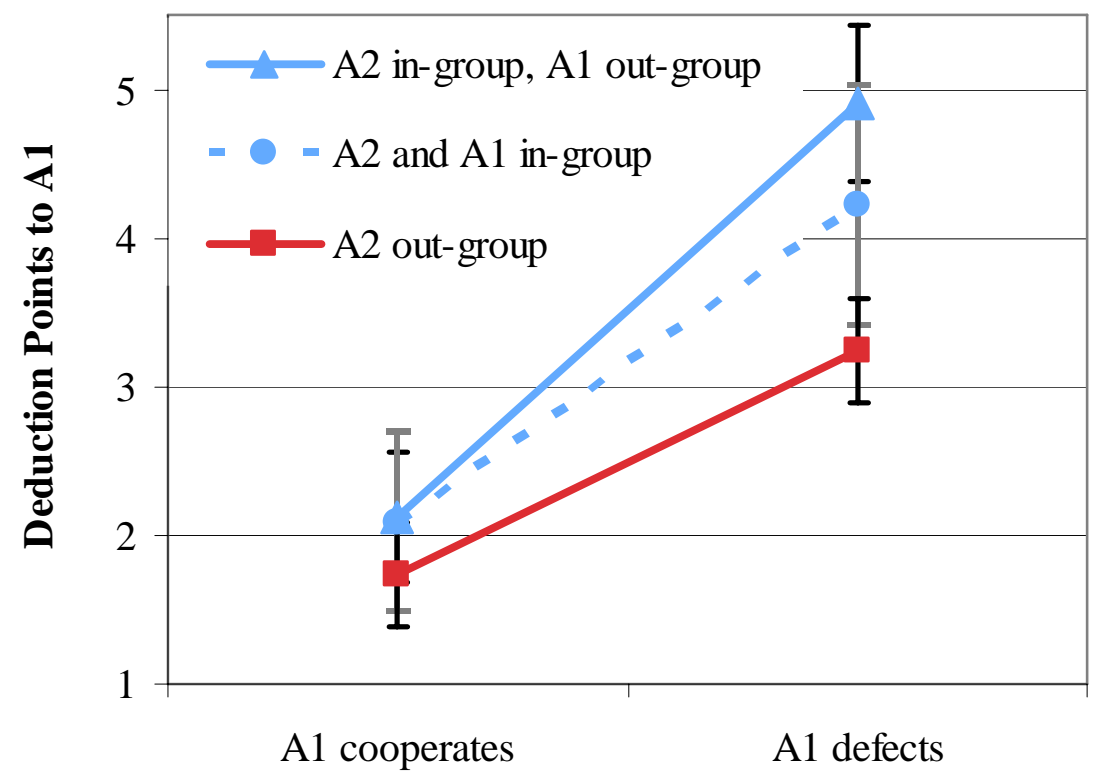

Behavior of A1

Figure 2: The Impact of A1's Group Membership on Third-Party Punishment 